\title{
Explosive pitting of 1018 steel witness plates
}

\author{
G. A. Walsh ${ }^{1} \&$ V. D. Romero ${ }^{2}$ \\ ${ }^{I}$ Department of Materials Science and Engineering, \\ New Mexico Institute of Mining and Technology, USA \\ ${ }^{2}$ Department of Physics, \\ New Mexico Institute of Mining and Technology, USA
}

\begin{abstract}
1018 steel witness plates were put into contact with the explosives Ammonium Nitrate and Fuel Oil (ANFO), composition C4, dynamite, flake trinitrotoluene (TNT), smokeless powder and black powder. Explosive-induced pitting of the metal targets was observed in tests involving C4, dynamite, TNT and smokeless powder. The microstructure directly under pitting sites was examined using standard metallographic techniques. No sign of melting was observed under or around the pits, indicating that pitting is most likely caused by impingement of hard particles on the metal surface during combustion of the explosive material, or by jet formation from the collapse of voids at the explosive/target interface.

Keywords: explosives, explosive pitting, explosive-metal interactions.
\end{abstract}

\section{Introduction}

Pitting is a phenomenon that occurs on metal surfaces in contact with, or very close proximity to, detonating explosives [1]. This pitting of metals is often used in forensic investigations to indicate the occurrence of an explosive event [1], [2]. The cause of explosive pitting is, however, the subject of some controversy. Pitting has been said to be caused by the impact of high velocity particles (either unconsumed explosive or inert) [3]. Another theory is that small jets formed by the collapse of voids at the explosive / metal interface produces pitting [4]. Additionally, claims have been made indicating that the explosive event generates enough heat to melt small portions of the metal surface, creating small pits upon solidification [5]. 


\subsection{High velocity impact}

The high velocity impact of a particle onto a metal surface causes pitting, or cratering, of the metal. An example microstructure of a copper target impacted by an aluminium projectile is shown in Figure 1 [6]. The target material's microstructure after such an impact is highly distorted; the grains have undergone dynamic recrystallization directly under the impact site, and appear flattened further into the sample.

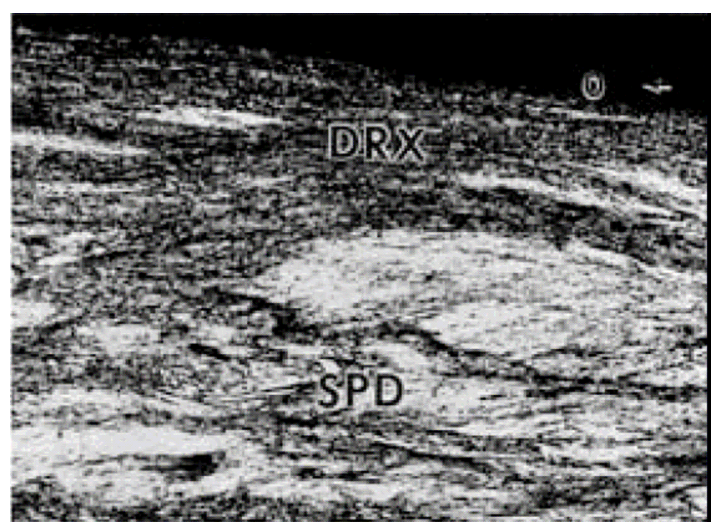

Figure 1: Dynamic recrystallization (DRX) and severe plastic deformation (SPD) under a crater in a copper target after impact by an aluminium projectile [6].
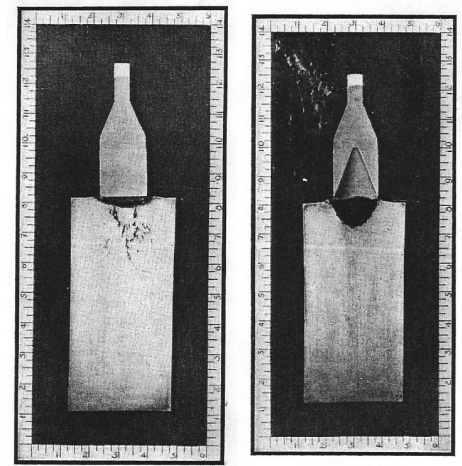

Figure 2: An illustration of the Monroe effect [7].

\subsection{The Monroe effect}

The Monroe effect, or the shaped charge effect, describes a focusing of the energy produced in an explosive detonation. This effect is illustrated in Figure 2 [7]. As the explosive material detonates, the cavity is collapsed, and a high 
energy jet is formed where the shock waves collide in the centre of the collapsing void. If a liner is inserted inside the cavity, the collapse of the liner generates a metallic jet, which is the basis for many modern anti-armour weapons [8].

The microstructure of a 1020 steel target impacted by a copper shaped charge jet is shown in Figure 3 [9]. In this figure, there is also a highly deformed grain structure and evidence of recrystallization.

\section{Penetration direction}

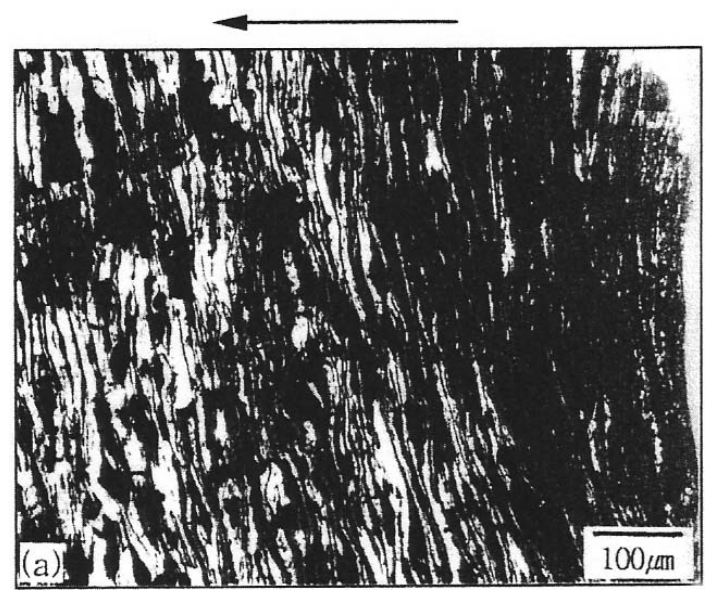

Figure 3: The effect of a copper shaped charge jet impact on the microstructure of a 1020 steel target [9].

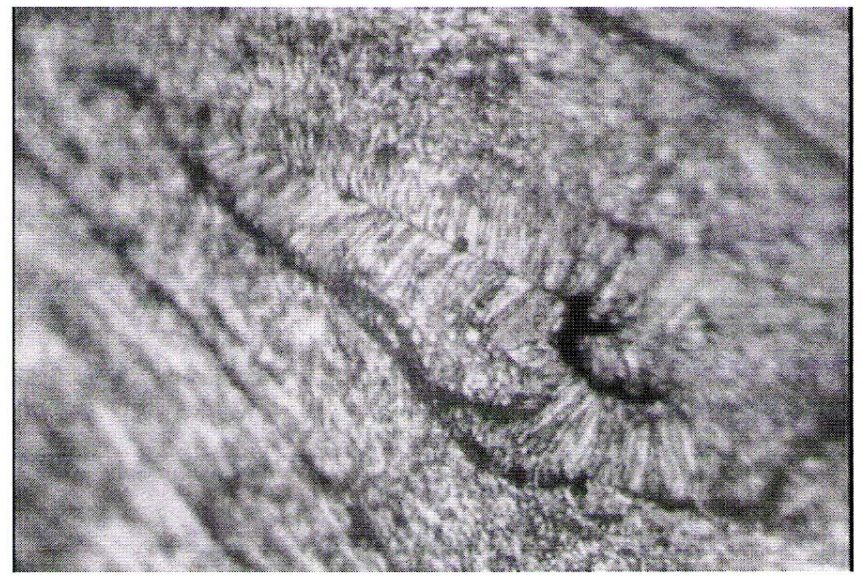

Figure 4: Evidence of melting in a copper/copper explosive weld interface [10]. 


\subsection{Melting}

The melting and re-solidification of metals creates a cast structure, such as that found in Figure 4, a micrograph indicative of melting at the interface of a copper/copper explosive weld [10]. This type of microstructure, or the presence of dendrites would be evidence of melting and re-solidification of a metal subjected to an explosive shock.

\section{Experimental procedure}

\subsection{Explosive testing}

In this study, six different types of explosives were used. The weights the explosives were varied in order to keep the same TNT equivalent weight of 0.82 lbs. By keeping the TNT equivalent weight the same for the various explosives, the air shock overpressure from all the blasts should be the same [11]. The explosives used and their weights are listed in Table 1. Each explosive was tested three times, for a total of 18 experiments.

Table 1: $\quad$ The types and weights of explosives used.

\begin{tabular}{|l|c|}
\hline Explosive & Weight used (lbs) \\
\hline Ammonium Nitrate and Fuel Oil (ANFO) & 1.1 \\
\hline Composition C4 & 0.61 \\
\hline Dynamite & 0.85 \\
\hline Flake Trinitrotoluene (TNT) & 0.82 \\
\hline Black Powder & 1.25 \\
\hline Smokeless Powder & 0.64 \\
\hline
\end{tabular}

The explosives were packed into 2" ID schedule 40 ASTM A53 steel pipe, the lengths of which were varied to accommodate the amount of explosive used. The pipes were threaded on one end, to accept a standard end cap. A nonelectric detonator was inserted in the top centre of the explosive charge. The explosive was in direct contact with a 3" x 3" 1018 steel witness plate, which had been ground with 80 grit $\mathrm{SiC}$ paper to ensure a smooth, pit-free surface. The assemblies were taken to the Energetic Materials Research and Testing Center (EMRTC), at the New Mexico Institute of Mining and Technology, for testing. After testing, the plates were recovered and saved for future characterization. Two of the plates were not recovered after testing.

\subsection{Metallography}

After collection, the surface of each witness plate was photographed, and the number of pits on the surface was counted and recorded. The plates were then cross sectioned, and a portion of the sample was mounted, ground and polished using standard metallurgical techniques and etched with Nital. After etching, the samples were imaged with a Versamet 2 Metallograph for optical microscopy. 


\section{Results}

\subsection{Pitting frequency}

The number of pits on the surface of each plate is listed in Table 2.

Table 2: $\quad$ Pitting frequency by explosive type $(\mathrm{N} / \mathrm{R}=$ plate not recovered).

\begin{tabular}{|l|c|c|c|c|}
\hline Explosive & Plate 1 & Plate 2 & Plate 3 & Average \\
\hline ANFO & 0 & 0 & N/R & 0 \\
\hline Comp. C4 & 6 & 4 & N/R & 5 \\
\hline Dynamite & 333 & 294 & 296 & 307.7 \\
\hline Flake TNT & 157 & 235 & 392 & 261.3 \\
\hline $\begin{array}{l}\text { Black } \\
\text { Powder }\end{array}$ & 0 & 0 & 0 & 0 \\
\hline Smokeless P. & 431 & 471 & 392 & 431.3 \\
\hline
\end{tabular}

\subsection{Pit cross-sections}

The microstructures of witness plates from the composition C4, dynamite, TNT and smokeless powder tests (Figure 5(a)-(d), respectively) show shallow pitting with severe deformation and recrystallization underneath the pit, whereas the reference sample (seen in Figure 5(e)) has a flat, uniform surface and equiaxed grain structure. One witness plate from an ANFO test revealed a microscopic pit upon metallographic examination, however, the damage to the grain structure is fairly limited, see Figure 6.

\section{Discussion}

\subsection{Pitting frequency}

Severe pitting was observed on witness plates subjected to the combustion of dynamite, flake TNT and smokeless powder. Minor pitting was noted on the plates after the detonation of $\mathrm{C} 4$. No visible pitting was seen on the surface of the ANFO witness plates; however, a small pit was found upon microscopic examination of the cross section of one plate. Black powder produced neither macroscopic nor microscopic pitting.

No clear correlation can be drawn between pitting frequency and explosive detonation velocity. This can be explained by differences in the consistency of the explosives used in this study. While $\mathrm{C} 4$ and ANFO are relatively homogeneous, soft materials, the other explosives studied consist of hard particles or, in the case of dynamite, have hard, particulate filler materials mixed into the explosive composition. 

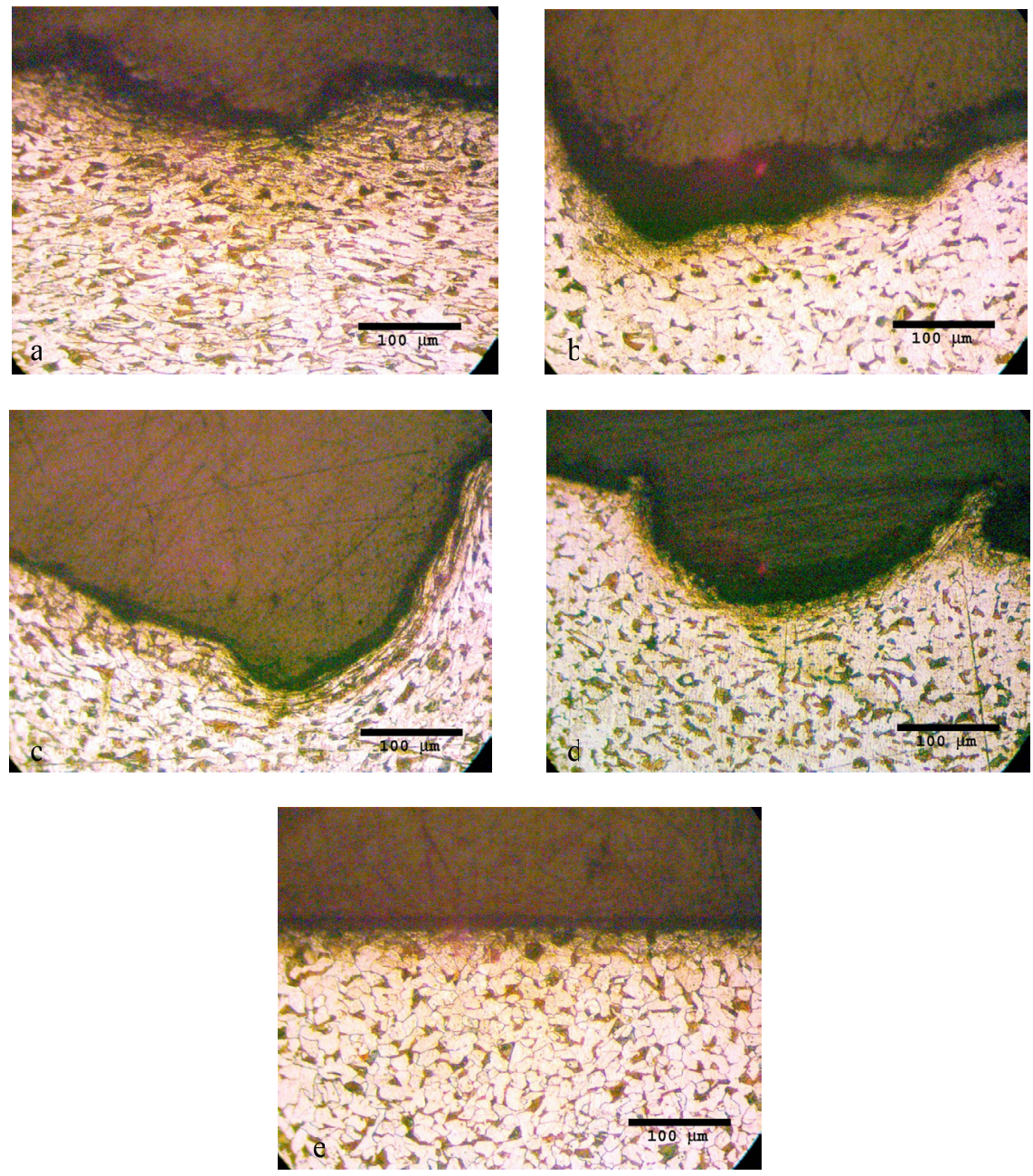

Figure 5: Recystallization and deformation of the witness plate grain structure from the (a) C4, (b) dynamite, (c) TNT and (d) smokeless powder tests; (e) is the reference sample.

\subsection{Pit morphology}

No evidence of melting and re-solidification was found in any of the plate cross sections. The microstructures obtained did appear similar to those found in previous work on both the impact of metals with hard objects and shaped charge jets.

Dynamite consistently supplied the largest pits, likely due to hard particles found within the dynamite. The dynamite material was removed from its casing and pressed into the metal pipe, flush against the witness plate prior to testing, making the probability of air pockets at the explosive/metal interface unlikely. 


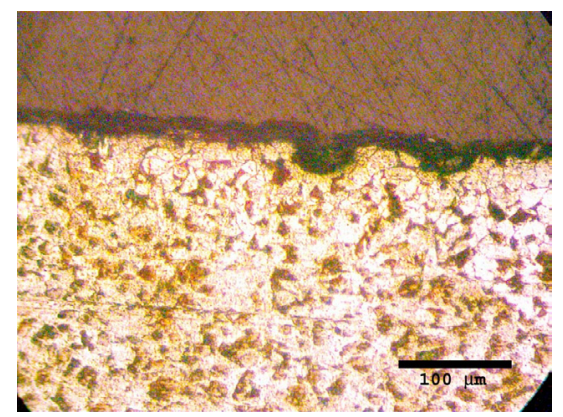

Figure 6: The microstructure under a small pit found in the ANFO witness plate.

Flake TNT and smokeless powder both generated a large number of pits. This pitting is likely due to the Monroe effect or a combination of the Monroe effect and denting. When preparing for testing, the flake TNT and smokeless powder were both poured into the pipe, and no effort was made to press them against the witness plate. This setup allows for the formation of many voids at the explosive/target interface, which could easily lead to Monroe effect-based jetting.

Composition $\mathrm{C} 4$ induced a small number of pits on the witness plates. The damage to the microstructure, however, was severe and penetrated fairly deep into the cross section of the material. The near-absence of pits is most likely due to the homogeneous and soft nature of $\mathrm{C} 4$. As in the dynamite test, this explosive was pressed against the witness plate to minimize the formation of air pockets at the target interface, but unlike dynamite, does not have hard particles in its makeup.

ANFO and black powder produced virtually no pitting, in these cases it is likely that low detonation velocity (in the case of ANFO) and burn rate (of black powder) minimized pitting. ANFO has a detonation velocity of $4.7 \mathrm{~km} / \mathrm{s}$, where the detonation velocities of the other high explosives used range from 6 to $8 \mathrm{~km} / \mathrm{s}$. The burn rate of black powder is on the order of tens of $\mathrm{m} / \mathrm{s}$. Additionally, ANFO is a soft, prill-type explosive, which is unlikely to dent a steel plate, even at high temperatures, pressures and velocities.

\section{Conclusions}

Pitting of 1018 steel witness plates was seen in dynamic tests involving composition C4, dynamite, flake TNT and smokeless powder. ANFO and black powder did not produce pitting. There is no clear correlation between pitting frequency and detonation velocity.

In examining the microstructure of metal targets after explosive experiments were carried out, no signs of melting were observed. The microstructures generated in this study were, however, consistent with those seen in the deformation of metal targets produced by the impact of hard projectiles and the impact of shaped charge jets. 


\section{Acknowledgements}

The authors would like to thank the US Department of Homeland Security for funding this research under grant \# RDJ9000. Also, thanks should be extended to the people of the Energetic Materials Research and Testing Center for their assistance in dynamic testing.

\section{References}

[1] United States of America vs. Terry Lynn Nichols. Oklahoma City Bombing Trial Transcript. CourtTV website. http://www.courttv.com/archive/casefiles/oklahoma/nichtranscripts/1125p m.html

[2] Loeb, B. Statement of Dr. Bernard S. Loeb, TWA Flight 800 Board Meeting, NTSB website. http://www.ntsb.gov/Speeches/s000822.htm

[3] United States of America vs. Timothy James McVeigh. Oklahoma City Bombing Trial - Transcripts. CNN website, Atlanta, GA. USA http://www.cnn.com/US/9703/okc.trial/transcripts/may/052097.eve.html? eref=sitesearch

[4] The FBI Laboratory: An Investigation into Laboratory Practices and Alleged Misconduct in Explosives-Related and Other Cases (April 1997). US Department of Justice website. http://www.usdoj.gov/oig/special/9704a/

[5] Smith, J.B. Aircraft Accident Report - Air India Flight 182 pp. 40, 2001.

[6] Murr, L.E., Trillo, E.A., Pappu, S. \& Kennedy, C. Adiabatic shear bands and examples of their role in severe plastic deformation. Journal of Materials Science, 37, pp. 3337-3360, 2002.

[7] Birkhoff, G., MacDougall, P., Pugh, E. \& Taylor, B. Explosives with cavities. Journal of Applied Physics, 19, pp. 563-582, 1948.

[8] Petit, J., Jeanclaude, V. \& Fressengeas, C. Breakup of copper shaped charge jets: experiment, numerical simulations and analytical modeling. Journal of Applied Physics, 98(12), 2005.

[9] Lee, S., Hong, M-H., Noh, J-W. \& Baek, W.H. Microstructural evolution of a shaped-charge liner and target materials during ballistic tests. Metallurgical and Materials Transactions A, 33A, pp. 1069-1074, 2003.

[10] Walsh, G.A.; Inal, O.T.; Lopez, D.H. \& Gerity, P.F. Wave amplitude and frequency seen at explosively welded copper/copper interfaces. Proceedings of Computer Methods and Experimental Measurements for Surface Effects and Contact Mechanics VII, eds. deHosson, J.T.M.; Brebbia, C.A. and Nishida, S.I. WIT Press: Boston, MA., pp. 23-31, 2005.

[11] Cooper, P.W. Explosives Engineering. VCH Publishers, New York, Wienheim and Cambridge, pp. 405-406, 1996. 